\title{
DIMENSÃO ECONÔMICA DO COMPLEXO LÁCTEO GAÚCHO ${ }^{1}$
}

\author{
Eduardo Belisário Finamore ${ }^{2}$ \\ Marco Antonio Montoya ${ }^{3}$
}

Resumo - Neste artigo procurou-se caracterizar e mensurar o complexo lácteo da economia do Estado do Rio Grande do Sul. A metodologia utilizou indicadores de performance setorial e índices de autonomia de compras e vendas para delimitar a mensuração do complexo lácteo. Os dados foram extraídos da matriz insumo-produto de 1998 disponibilizada pela FEE do RS. Verificou-se que o complexo lácteo gaúcho é um grande produtor de leite nacional e seu nível de competitividade o situa entre os mais eficientes produtores do país. O complexo lácteo responde, a preço básico, por 6,77\% do PIB do agronegócio gaúcho está fortemente vinculado ao setor urbano de forma direta e emprega 118.603 trabalhadores, o que perfaz $5,07 \%$ e $2,42 \%$ do total de trabalhadores do agronegócio e do estado, respectivamente. A partir da parcela do valor adicionado apropriado pelos trabalhadores, identificou-se que a agroindústria do leite detém processos produtivos modernos, com tecnologias mais intensivas no uso de capital que de mão-de-obra. Portanto, conclui-se que o complexo lácteo constitui-se num importante componente do agronegócio gaúcho e que seu desempenho, dados os fortes encadeamentos que apresenta com o setor urbano, é fundamental para o desenvolvimento econômico do estado.

Palavras-chave: complexo lácteo, insumo-produto, PIB, emprego, salário.

\footnotetext{
Recebido em 19/01/2005

Aceito em 25/03/2005

2 Professor da Faculdade de Ciências Econômicas, Administrativas e Contábeis da Universidade (FEAC) de Passo Fundo (UPF), RS. Pesquisador do Centro de Pesquisa e Extensão da FEAC e Doutor em Economia Rural pela Universidade Federal de Viçosa. E-mail: finamore@upf.tche.br

3 Professor Titular da Faculdade de Ciências Econômicas, Administrativas e Contábeis da Universidade (FEAC) de Passo Fundo (UPF), RS. Pesquisador do Centro de Pesquisa e Extensão da FEAC e Doutor em Economia Aplicada pela Escola Superior de Agricultura Luiz de Queiroz (ESALQ) da Universidade de São Paulo. Email: montoya@upf.tche.br
} 


\section{Introdução}

O conjunto de políticas nacionais, iniciadas no final da década de 1980 e aceleradas na de 1990, tinha como objetivos a desregulamentação do mercado, a estabilização da economia e a abertura comercial. Como resultado, o complexo lácteo do Rio Grande do Sul passou, na década de 1990, por mudanças estruturais profundas, uma vez que essas políticas promoveram no setor: a liberalização e diferenciação dos preços da matéria-prima, as guerras de ofertas nas prateleiras dos supermercados, a entrada de produtos importados, as alianças estratégicas no meio empresarial, a ampliação do poder dos laticínios multinacionais e dos supermercados, a ampliação da coleta ao granel, a redução global do numero de produtores, a reestruturação geográfica da produção, etc. (Jank, 2000).

As mudanças estruturais no complexo lácteo assinalam ganhos de produtividade na produção de leite natural em razão do maior grau de articulação com a indústria processadora. Não em poucos casos, os níveis de articulação chegam a uma integração vertical total, já que, por um lado, a indústria láctea se integra para trás, controlando e coordenando a produção de leite natural e, por outro, os produtores de leite avançam para frente e industrializam sua produção, ou ambos os processos simultaneamente, isto é, indicando uma dinâmica conjunta da produção agropecuária com as agroindústrias e, em decorrência, com os agrosserviços.

Diante desses fatos e a fim de compreender melhor o contexto econômico global que envolve as atividades do complexo lácteo, o artigo procura, por um lado, salientar alguns aspectos do desempenho do complexo lácteo nos contextos nacional e regional e, por outro, propõe-se, para o ano de 1998, mensurar, com base numa perspectiva sistêmica, o PIB, o número de empregos e a renda salarial do complexo lácteo gaúcho. Com isso, espera-se fornecer elementos concretos que contribuam com o tema, até porque, com a avaliação da performance econômica e com a mensuração do complexo lácteo no sistema econômico, é possível 
caracterizar elementos fundamentais para o desenho de políticas econômicas e sociais que induzam um maior desenvolvimento do agronegócio gaúcho.

O artigo está dividido da seguinte maneira: a seção 2 descreve, de forma sucinta, a base de dados utilizados e a metodologia de mensuração do complexo lácteo; a seção 3 avalia o desempenho do complexo lácteo gaúcho a partir de indicadores de performance setorial, como produção e produtividade; a seção 4, considerando a dimensão do agronegócio e da economia gaúcha como um todo, avalia de forma comparativa o PIB, o número de empregos e a renda salarial que gera o complexo lácteo gaúcho; finalmente, as principais conclusões obtidas no decorrer das análises são apresentadas na última seção.

\section{Metodologia}

Para avaliar o desempenho do complexo lácteo gaúcho nos contextos nacional e regional, são utilizados indicadores de performance setorial, como produção e produtividade. Esses indicadores são analisados de forma comparativa perante os panoramas nacional e regional, com o objetivo de situar a importância relativa do complexo lácteo gaúcho no ranking nacional.

Para o cálculo do complexo lácteo, utilizaram-se como referencial as metodologias de Davis e Goldberg (1957), Malassis (1969), bem como as contribuições de Furtuoso (1998), Montoya e Guilhoto (2000), da Confederação Nacional da Agricultura (CNA) e Universidade de São Paulo, desenvolvida por Guilhoto et al. (2000), de Finamore (2001), Montoya et al. (2001) e Finamore e Montoya (2003), que vieram a superar gradativamente os problemas de dupla contagem na mensuração dos principais agregados do agronegócio.

Cabe salientar que, diferentemente de outras metodologias sobre o dimensionamento do agronegócio, que pretendem captar os segmentos 
do setor serviços a partir de coeficientes técnicos de produção, a linha de pensamento dos trabalhos supracitados tem como hipótese central estimar os serviços da economia a partir do consumo final, visto que nessas informações se encontra o total de serviços agregados sobre produtos e subprodutos do agronegócio no processo circular da economia, distribuindo-se de modo homogêneo por todos os setores. Com isso, evitamse riscos de subestimar a dimensão do agronegócio.

A fim de definir o valor do produto agroindustrial derivado do leite, utilizouse o índice de autonomia de compras e vendas, estimado por Montoya e Finamore (2004), com o objetivo de delimitar o complexo lácteo gaúcho. Naquele trabalho, verificou-se que os setores de Leite Natural (setor 5) e Leite Beneficiado e Outros Laticínios (setor 24) apresentam um nível elevado de autonomia no suprimento de insumos, tanto para as vendas $(99,54 \%)$ quanto para as compras $(77,92 \%)$.

Para a operacionalização desse modelo proposto, foi necessária a compilação de uma matriz insumo-produto com tecnologia produto-produto de dimensão 43 x 43 setores comuns (ver a descrição dos setores no Anexo 1). Com isso, foi possível desagregar o setor Leite Natural (setor 5) da agropecuária, que, numa tecnologia indústria-indústria, incorporava vários produtos tanto da agricultura quanto da pecuária.

\subsection{Mensuração do complexo lácteo}

Nesta seção são ilustrados os procedimentos adotados para a estimativa do PIB do complexo lácteo, que se dá pelo enfoque do produto a preços básicos. Serão utilizados, portanto, dois setores basicamente, o de Leite Natural e o de Leite Beneficiado e Outros Laticínios, conforme a delimitação do cluster do leite estabelecido pelos índices de autonomia estimados por Montoya e Finamore (2003). 
O valor total do PIB do complexo lácteo será dividido em: a) agregado I ou insumos do leite; b) agregado II ou produção do leite; c) agregado III ou agroindústria do leite; e d) agregado IV ou agrosserviços do leite. Para a quantificação do agregado I, consideram-se como a montante do complexo lácteo os insumos adquiridos pelo setor Leite Natural (setor 5), base do agregado II. O agregado III, ou agroindústria do leite, foi constituído pelo setor Leite Beneficiado e Outros Laticínios (setor 24). Já o agregado IV, ou agrosserviços, foi constituído pela parcela dos setores de serviços da economia gaúcha, responsáveis pela comercialização tanto do leite natural (setor 5) quanto do leite beneficiado e outros laticínios (setor 24).

Para o cálculo do PIB do agregado I são utilizadas as informações disponíveis nas tabelas de insumo-produto, compiladas numa tecnologia produto-produto, referentes aos valores dos insumos adquiridos pelos produtores de leite natural (setor 5). A coluna com os valores dos insumos é multiplicada pelos respectivos coeficientes de valor adicionado $\left(C V A_{q}\right)$. Para obter os Coeficientes do Valor Adicionado por atividade $\left(C V A_{q}\right)$, divide-se o Valor Adicionado a Preços básicos $\left(V A_{P B q}\right)$ pela Produção da atividade $\left(X_{q}\right)$, ou seja:

$$
C V A_{q}=\frac{V A_{P Q q}}{X_{q}}
$$

Tem-se, então:

$$
\begin{aligned}
& P I B_{I}=\sum_{q=1}^{n} Z_{q} \times C V A_{q} \\
& q=1,2, \ldots, 43 \text { produtos ou atividades } \\
& \text { em que: }
\end{aligned}
$$


$P I B_{I}=$ PIB do agregado I (insumos) do complexo lácteo;

$Z_{q}=$ valor total do insumo da atividade $q$ para a produção de leite natural; $\mathrm{e}$

$C V A_{q}=$ coeficiente de valor adicionado da atividade $q$.

Ou seja, para se estimar o valor adicionado do agregado I, ou setor a montante do complexo lácteo, multiplicam-se os valores comprados pela produção de leite natural de cada atividade pelo coeficiente de valor adicionado dessas atividades. Salienta-se que, para se evitar dupla contagem, esses valores estimados devem ser subtraídos dos outros agregados a seguir, de forma a não haver dupla contagem.

Para o agregado II, considera-se no cálculo o valor adicionado gerado pela produção de leite natural (setor 5) e subtraem-se do valor adicionado desse setor os valores que foram utilizados como insumos, que já foram incorporados no PIB do agregado I. Tem-se, então, que:

$P I B_{I I}=V A_{P B q l}-Z_{q l} \times C V A_{q l}$

em que:

$\mathrm{Z}_{\mathrm{ql}}=$ valor do insumo da agropecuária adquirido pela própria atividade de leite natural; e

$P I B_{I I}=$ PIB do agregado II para a atividade leite natural.

No caso da estimação do agregado III (a agroindústria do leite), adotase o somatório do valor adicionado da atividade leite beneficiado e outros laticínios (setor 24), subtraído do valor adicionado desse setor que foi utilizado como insumo do agregado I, ou seja: 


$$
P I B_{I I}=\sum_{q a l}\left(V A_{P B_{a a l}}-Z_{q a l} \times C V A_{q a l}\right)
$$

em que:

$\mathrm{Z}_{\text {qal }}=$ valor do insumo da agroindústria do leite beneficiado adquirido pela produção de leite; e

$$
P I B_{I I I}=\text { PIB do agregado III do complexo lácteo. }
$$

No caso do agregado IV, referente à Distribuição Final, considera-se para fins de cálculo o valor agregado dos setores relativos a transporte, comércio e segmentos de serviços. Do valor total obtido, destina-se ao complexo lácteo apenas a parcela que corresponde à participação dos produtores de leite e agroindustriais do leite na demanda final de produtos.

A sistemática adotada no cálculo do valor da distribuição final do complexo lácteo pode ser representada por:

$$
\begin{aligned}
& D F G-I I L_{D F}-P I_{D F}=D F D \\
& \left(V A T_{P B}+V A C_{P B}+V A S_{P B}\right)-\left(Z_{q s} \times C V A_{q s}\right)=M C \\
& P I B_{I V}=M C \times \frac{D F_{q l}+\sum_{q a l} D F_{q a l}}{D F D}
\end{aligned}
$$

em que:

$D F G=$ demanda final global;

$I I L_{D F}=$ impostos indiretos líquidos pagos pela demanda final;

$P I_{D F}=$ produtos importados pela demanda final;

$D F D=$ demanda final doméstica;

$V A T_{P B}=$ valor adicionado do setor transporte a preços básicos;

$V A C_{P B}=$ valor adicionado do setor comércio a preços básicos;

$V A S_{P B}=$ valor adicionado do setor serviços a preços básicos; 
$\mathrm{Z}_{\mathrm{qs}}=$ valor do insumo dos setores de serviços adquiridos pelos produtores de leite;

$M C=$ margem de comercialização;

$D F_{q l}=$ demanda final doméstica da produção de leite natural;

$D F_{q a l}=$ demanda final doméstica do setor da agroindústria do leite; e

$P I B_{I V}=$ PIB do agregado IV para a produção de leite e da agroindústria do leite.

Para evitar uma dupla contagem no cálculo do PIB do complexo lácteo, é necessário subtrair as parcelas de insumos utilizados nos setores de serviços, pertencentes ao agregado I, do valor adicionado do setor de serviços (fórmula 6).

O PIB total do complexo lácteo é dado pela soma dos seus agregados, ou seja:

$P I B_{\text {Complexo Lácteo }}=P I B_{I}+P I B_{I I}+P I B_{I I I}+P I B_{I V}$

2.2 Mensuração da mão-de-obra ocupada e da renda salarial

Para se obter tanto a mão-de-obra ocupada como a renda salarial de cada agregado do complexo lácteo, o processo metodológico é similar ao da obtenção do PIB, numa visão sistêmica, apresentada anteriormente. Contudo, são necessárias algumas adequações, mostradas nas fórmulas seguintes.

2.2.1 Mensuração da mão-de-obra dos agregados

$C L_{q}=\frac{L_{q}}{X_{q}}$

em que: 
$\mathrm{L}_{\mathrm{q}}=$ número de trabalhadores por atividade; e

$\mathrm{CL}_{\mathrm{q}}=$ coeficiente de trabalhadores por atividade.

$E_{I}=\sum_{q=1}^{n} Z_{q} \times C L_{q}$

$q=1,2, \ldots, 43$ atividades

em que:

$\mathrm{E}_{\mathrm{I}}=$ número de trabalhadores do agregado $\mathrm{I}$.

$E_{I I}=L_{q l}-Z_{q l} X C L_{q l}$

em que:

$\mathrm{L}_{\mathrm{ql}}=$ número de trabalhadores da atividade leite natural;

$\mathrm{CL}_{\mathrm{ql}}=$ coeficiente de trabalho da produção de leite natural; e

$\mathrm{E}_{\mathrm{II}}=$ número de trabalhadores do agregado II.

$E_{I I I}=\sum_{q a l}\left(L_{q a l}-Z_{q a l} \times C L_{q a l}\right)$

em que:

$\mathrm{L}_{\text {qal }}=$ número de trabalhadores da atividade leite beneficiado e outros laticínios; e

$\mathrm{E}_{\mathrm{III}}=$ número de trabalhadores do agregado III. 


$$
\begin{aligned}
& D F G-I I L_{D F}-P I_{D F}=D F D \\
& (L T+L C+L S)-\left(Z_{q s} X C L_{q s}\right)=L C M \\
& L_{I V}=L C M \times \frac{D F_{q l}+\sum_{q a l} D F_{q a l}}{D F D}
\end{aligned}
$$

em que:

$\mathrm{LT}=$ número de trabalhadores do setor transporte;

LC = número de trabalhadores do setor comércio;

$\mathrm{LS}=$ número de trabalhadores do setor serviços;

$\mathrm{CL}_{\mathrm{qs}}=$ coeficiente de trabalho dos setores de comercialização;

LCM = número de trabalhadores nos setores de comercialização;

$\mathrm{L}_{\mathrm{IV}}=$ número de trabalhadores do agregado IV;

$\mathrm{DF}_{\mathrm{ql}}=$ demanda final da produção de leite natural; e

$\mathrm{DF}_{\text {qal }}=$ demanda final da agroindústria do leite.

O total de trabalhadores do complexo lácteo é dado pela soma dos seus agregados, ou seja:

$$
\mathrm{L}_{\text {Complexo Lácteo }}=L_{I}+L_{I I}+L_{I I I}+L_{I V}
$$

2.2.2 Mensuração da renda salarial dos agregados

$$
C S_{q}=\frac{S_{q}}{X_{q}}
$$

em que: 
$\mathrm{S}_{\mathrm{q}}=$ renda salarial por atividade; $\mathrm{e}$

$\mathrm{CS}_{\mathrm{q}}=$ coeficiente de salários por atividade.

$S_{I}=\sum_{q=1}^{n} Z_{q} \times C S_{q}$

$\mathrm{q}=1,2, \ldots, 43$ atividades

em que:

$\mathrm{S}_{\mathrm{I}}=$ renda salarial do agregado $\mathrm{I}$.

$S_{I I}=S_{q l}-Z_{q l} \times C S_{q l}$

em que:

$\mathrm{S}_{\mathrm{ql}}=$ renda salarial do setor da atividade leite natural;

$\mathrm{CS}_{\mathrm{ql}}=$ coeficiente de salários da produção de leite natural; e

$\mathrm{E}_{\mathrm{II}}=$ renda salarial do agregado II.

$S_{I I I}=\sum_{q a l}\left(S_{q a l}-Z_{q a l} \times C S_{q a l}\right)$

em que:

$\mathrm{CS}_{\text {qal }}=$ coeficiente de salários da agroindústria do leite; e

$\mathrm{S}_{\mathrm{III}}=$ renda salarial do agregado III.

$D F G-I I L_{D F}-P I_{D F}=D F D$ 
$(S T+S C+S S)-\left(Z_{q s} x C S_{q s}\right)=S C$

$S_{I V}=S C \times \frac{D F_{q l}+\sum_{q a l} D F_{q a l}}{D F D}$

em que:

ST = renda salarial do setor transporte;

$\mathrm{SC}=$ renda salarial do setor comércio;

$\mathrm{SS}=$ renda salarial do setor serviços;

$\mathrm{CS}_{\mathrm{qs}}=$ coeficiente de salários dos setores de comercialização;

$\mathrm{SC}=$ renda salarial nos setores de comercialização; e

$\mathrm{S}_{\mathrm{IV}}=$ renda salarial do agregado IV.

A renda salarial total do agronegócio é dada pela soma dos seus agregados, ou seja:

$\mathrm{S}_{\text {Complexo lácteo }}=S_{I}+S_{I I}+S_{I I I}+S_{I V}$

\subsection{Fonte de dados}

Os dados foram extraídos das tabelas de insumo-produto e das contas econômicas integradas do Rio Grande do Sul do ano de 1998, fornecidas pela Fundação de Economia e Estatística (FEE). As informações utilizadas são a preços básicos e encontram-se em milhões de reais de 1998. Para a compilação das matrizes, adotou-se o modelo produto-produto com tecnologia baseada na indústria. Em geral, as estatísticas do estado utilizadas representam as últimas informações disponíveis em matéria de insumo-produto; portanto, o presente estudo, baseado na fonte empregada, tem o grau máximo de atualização possível. 


\section{Performance setorial do Complexo Lácteo do Rio Grande do Sul}

A fim de situar em termos relativos o desempenho da produção de leite do complexo lácteo em níveis nacional e regional, são apresentados a seguir indicadores de produção e produtividade para o período de 1991 a 2002.

Como mostra a Tabela 1, o Rio Grande do Sul constitui-se no terceiro maior produtor nacional de leite, com uma produção de 2.333 milhões de litros no ano de 2002, segundo dados da Embrapa Gado de Leite, perdendo apenas para Minas Gerais (6.177 milhões/litros) e Goiás (2.483 milhões/ litros). Já em termos de produtividade, para esse ano, o produtor gaúcho situa-se, no âmbito nacional, em primeiro lugar, com uma produtividade de 1.964 litros/vaca/ano. Em virtude desses fatos, pode-se afirmar que o Estado do Rio Grande do Sul é um grande produtor de leite no âmbito nacional e seu nível de produtividade coloca seus produtores como os mais eficientes do país. 
Tabela 1 - Ranking da produção anual de leite por estado no Brasil 2002

\begin{tabular}{|c|c|c|c|c|}
\hline Ranking & Estados & $\begin{array}{l}\text { Produc ão de Leite } \\
\text { (milhões de litros) }\end{array}$ & $\begin{array}{l}\text { Produtividade } \\
\text { (limosivaca) }\end{array}$ & $\begin{array}{c}\text { Produtiridade } \\
\text { (litros/hab.) }\end{array}$ \\
\hline $1^{\circ}$ & Minas Gerais & 6.177 & 1.351 & 328 \\
\hline $2^{\circ}$ & Goiás & 2.483 & 1.120 & 439 \\
\hline $3^{\circ}$ & Rio Grande do Sul & 2.330 & 1.964 & 206 \\
\hline $4^{\circ}$ & Paraná & 1.985 & 1.672 & 188 \\
\hline $5^{\circ}$ & São Paulo & 1.748 & 1.018 & 50 \\
\hline $6^{\circ}$ & Santa Catarina & 1.193 & 1.950 & 187 \\
\hline $7^{\circ}$ & Bahia & 752 & 496 & 55 \\
\hline $8^{\circ}$ & Rondônia & 644 & 978 & 306 \\
\hline $9^{\circ}$ & Pará & 577 & 582 & 61 \\
\hline $10^{\circ}$ & Mato Grosso do Sul & 472 & 987 & 33 \\
\hline $11^{\circ}$ & Mato Grosso & 467 & 1.072 & 206 \\
\hline $12^{\circ}$ & Rio de Janeiro & 447 & 1.150 & 169 \\
\hline $13^{\circ}$ & Pemambuco & 392 & 1.036 & 122 \\
\hline $14^{\circ}$ & Espírito Santo & 375 & 1.108 & 45 \\
\hline $15^{\circ}$ & Ceará & 341 & 768 & 45 \\
\hline $16^{\circ}$ & Alagoas & 224 & 1.376 & 77 \\
\hline $17^{\circ}$ & Maranhão & 195 & 528 & 135 \\
\hline $18^{\circ}$ & Tocantins & 186 & 463 & 27 \\
\hline $19^{\circ}$ & Rio Grande do Norte & 158 & 829 & 52 \\
\hline $20^{\circ}$ & Paraiba & 117 & 659 & 65 \\
\hline $21^{\circ}$ & Sergipe & 112 & 856 & 31 \\
\hline $22^{\circ}$ & Acre & 104 & 824 & 73 \\
\hline $23^{\circ}$ & Piauí & 75 & 381 & 27 \\
\hline $24^{\circ}$ & Amazonas & 40 & 550 & 13 \\
\hline $25^{\circ}$ & Distrito Federal & 37 & 1.355 & 18 \\
\hline $26^{\circ}$ & Roraima & 8 & 409 & 31 \\
\hline \multirow[t]{2}{*}{$27^{\circ}$} & Amapá & 3 & 556 & 8 \\
\hline & TOTAL & 21.644 & 13.206 & 116 \\
\hline
\end{tabular}


A análise da participação relativa das macrorregiões no panorama nacional no ano de 2002 (Tabela 2) mostra a Região Sudeste como a maior produtora de leite do país $(40,42 \%)$, seguida pelas regiões Sul $(25,45 \%)$, Centro-Oeste $(15,98 \%)$, Nordeste $(10,93 \%)$ e Norte $(7,22 \%)$.

Nesse contexto, as informações sobre a produção de leite, o tamanho do rebanho e as vacas ordenhadas permitem verificar que, entre os anos de 2000 e 2002, o Rio Grande do Sul manteve sua participação relativa de forma estável, em torno de $10,7 \%, 7,8 \%$ e $6,4 \%$, respectivamente. Contudo, a análise do crescimento do setor lácteo gaúcho nesse período mostra ganhos de 10,83\% na produção de leite, 5,66\% no rebanho e $1,84 \%$ no número de vacas ordenhadas. Esse nível de crescimento diferenciado no setor lácteo, em particular o da produção de leite e as vacas ordenhadas, indica claramente significativos ganhos de produtividade no período, isto é, a produtividade cresceu de 1.804 a 1.964 litros/vaca/ano, o que equivale a um aumento de $8,87 \%$ na produtividade. 
Tabela 2 - Panorama nacional do setor lácteo - período 2000 a 2002

\begin{tabular}{|c|c|c|c|c|c|c|c|c|c|}
\hline \multirow{2}{*}{$\begin{array}{l}\text { Unidades e } \\
\text { Macrorregiốes }\end{array}$} & \multicolumn{3}{|c|}{$\begin{array}{c}\text { Produc ão } \\
\text { tmilhöes de litros) }\end{array}$} & \multicolumn{3}{|c|}{$\begin{array}{c}\text { Rebanho } \\
\text { (mill (abey as) }\end{array}$} & \multicolumn{3}{|c|}{$\begin{array}{l}\text { Vacas Orderinadas } \\
\text { (mil cabeg as) }\end{array}$} \\
\hline & 2000 & 2001 & 2002 & 2000 & 2001 & 2002 & 2000 & 2001 & 2002 \\
\hline Rondô & 422 & 476 & 644 & 5.664 & 6.605 & 8.040 & 459 & 498 & 659 \\
\hline Acre & 41 & 86 & 104 & 1.033 & 1.673 & 1.817 & 69 & 107 & 126 \\
\hline Amazonas & 37 & 38 & 40 & 843 & 864 & 895 & 65 & 67 & 72 \\
\hline Roraima & 10 & 9 & 8 & 480 & 438 & 423 & 24 & 22 & 20 \\
\hline Pará & 380 & 459 & 577 & 10271 & 11047 & 12.191 & 801 & 758 & 990 \\
\hline Amapá & 4 & 3 & 3 & 83 & 7 & 4 & 6 & 6 & 6 \\
\hline Tocantins & 156 & 166 & 186 & 6.142 & 6.571 & 6.979 & 347 & 369 & 402 \\
\hline $\begin{array}{l}\text { Macomegião } \\
\text { Norte }\end{array}$ & 1.050 & .237 & 1562 & 245 & 27284 & 30 & 2 & 1.826 & .275 \\
\hline Marar & 150 & 155 & 195 & & & & 304 & 313 & 370 \\
\hline Piauí & 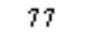 & 78 & 75 & 1.779 & 92 & & 28 & 195 & 197 \\
\hline Ceará & 332 & 328 & 341 & 06 & 94 & 80 & 441 & 437 & 444 \\
\hline Rio Grande do & 145 & 143 & 158 & 804 & 788 & 839 & 178 & 178 & 191 \\
\hline Paraiba & 106 & 106 & 117 & 953 & 918 & 952 & 176 & 171 & 178 \\
\hline Perrambuco & 292 & 360 & 392 & 1.516 & 1.673 & 53 & 321 & 359 & 378 \\
\hline Alago as & 218 & 244 & 224 & 770 & 843 & 816 & 160 & 173 & 163 \\
\hline Serzipe & 115 & 3 & 1 & 0 & 56 & 3 & 2 & 1 & 131 \\
\hline Bahia & 725 & 739 & 752 & 9.557 & 9.856 & 9.856 & 1.509 & 1.522 & 1.516 \\
\hline $\begin{array}{l}\text { Macromegião } \\
\text { Nordeste }\end{array}$ & 2.159 & 2.266 & 2366 & 67 & 14 & & 13 & 3.480 & .567 \\
\hline Minas Gerais & 5.865 & 5.981 & 6.177 & 19975 & 20219 & 20 & 4.415 & 4.475 & 4.574 \\
\hline Espirito Santo & 378 & 362 & 375 & 1.825 & 1.665 & 1.683 & 329 & 320 & 338 \\
\hline Rio de Jameiro & 469 & 447 & 447 & 1.959 & 1.977 & 1.981 & 392 & 390 & 389 \\
\hline Sto Paulo & 1.861 & 1.783 & 1.748 & 13092 & 13258 & 13.701 & 1.791 & 1.732 & 1.717 \\
\hline $\begin{array}{l}\text { Macomegião } \\
\text { Sudeste }\end{array}$ & 4 & 3 & 8 & 2 & 19 & 4 & 7 & 17 & 19 \\
\hline & & & & & & & & & 1.187 \\
\hline Santa Catarina & 1.003 & 1.076 & 1.193 & 3.051 & 3.096 & & 577 & 599 & 612 \\
\hline Rio Grande do Sul & 2.102 & 2.222 & 2330 & 13601 & 13872 & 14371 & 1.165 & 1.204 & 1.186 \\
\hline Macrorregião Sul & 4.904 & 5.188 & 5508 & 26298 & 26.784 & 27537 & 2.897 & 2.954 & 2.985 \\
\hline Iato Grosso do Sul & 427 & 445 & 472 & 22205 & 22620 & 23.168 & 444 & 458 & 478 \\
\hline Mato Grosso & 423 & 443 & 467 & 18925 & 19922 & 22.184 & 401 & 413 & 436 \\
\hline Go ós & 2.194 & 2.322 & 2.483 & 18399 & 19.132 & 20.102 & 2.006 & 2.121 & 2.217 \\
\hline Distrito Federal & 36 & 37 & 37 & 112 & 113 & 113 & 25 & 26 & 27 \\
\hline $\begin{array}{c}\text { Maromegião } \\
\text { Centro-0este } \\
\text { Brasil }\end{array}$ & $\begin{array}{r}3.080 \\
19.767\end{array}$ & $\begin{array}{l}3.246 \\
20.510\end{array}$ & 160 & $\begin{array}{r}641 \\
9.876\end{array}$ & $\begin{array}{l}1.787 \\
6.389\end{array}$ & 85 & 77 & 3.018 & 159 \\
\hline
\end{tabular}


Salienta-se, segundo Jank (2000), que, na década de 1990, a desregulação do mercado e a abertura comercial promoveram no setor lácteo mudanças estruturais profundas, como a liberalização e diferenciação dos preços do leite natural, maior concorrência de produtos lácteos nos supermercados, ampliação do poder de mercado dos laticínios, redução do número de produtores, entre outras.

Nesse contexto, convém enfatizar que o crescimento da produção do Rio Grande do Sul não é recente, pois o estado gaúcho vem apresentando crescimento constante a partir do ano de 1991 e, em decorrência disso, uma maior participação relativa na produção nacional: em 1991, o estado produziu 1.488 milhões de litros; em 1996, 1.861 milhões; e, em 2002, foi para 2.330 milhões de litros, fazendo com que o estado contribuísse com $10,76 \%$ da produção nacional, que em 2002 foi de 21.644 milhões de litros (Tabela 3).

Tabela 3 - Principais mesorregiões produtoras do RS - 1991- 2002

\begin{tabular}{|c|c|c|c|c|c|c|c|c|}
\hline \multirow{2}{*}{ Mesorregiăo Geográfica } & \multicolumn{4}{|c|}{$\begin{array}{l}\text { Produçăo de Leite } \\
\text { (milhöes linos) }\end{array}$} & \multicolumn{4}{|c|}{$\begin{array}{l}\text { Produtividade } \\
\text { (1imosivaca) }\end{array}$} \\
\hline & 1991 & 1996 & 2001 & 2002 & 1991 & 1996 & 2001 & 2002 \\
\hline Noroeste Rio-Grandense & 647 & 1.011 & 1.293 & 1.332 & 1.394 & 1.971 & 2.120 & 2.205 \\
\hline Hordeste Rio-Grandense & 199 & 197 & 233 & 292 & 1.234 & 1.653 & 1.372 & 1.845 \\
\hline Centro Ocidental Rio-Grandense & 67 & 73 & 93 & 95 & 945 & 1.219 & 1.220 & 1.222 \\
\hline Centro Orie ntal Rio-Grandense & 164 & 206 & 201 & 205 & 1.255 & 1.848 & 1.814 & 1.864 \\
\hline Metropolitana de Porto Alegre & 213 & 165 & 169 & 165 & 1.316 & 1.784 & 1.896 & 1.942 \\
\hline Sudoeste Rio-Grandense & 91 & 86 & 96 & 99 & 925 & 1.475 & 1.521 & 1.574 \\
\hline Sudeste Rio-Grandense & 109 & 124 & 138 & 142 & 1.077 & 1.604 & 1.606 & 1.603 \\
\hline Rio Grande do Sul & 1.488 & 1.861 & 2.222 & 2.330 & 1.254 & 1.805 & 1.845 & 1.964 \\
\hline
\end{tabular}


Cabe salientar, entretanto, que o incremento da produção de leite no Rio Grande do Sul esteve acompanhado também de aumentos permanentes de eficiência na produção em todo o período analisado. Isso porque, de 1991 a 2002, os níveis de produtividade foram crescentes, passando de 1.254 para 1.964 litros por vaca ao ano, ou seja, um aumento de 56,62\% em produtividade (Figura 1).

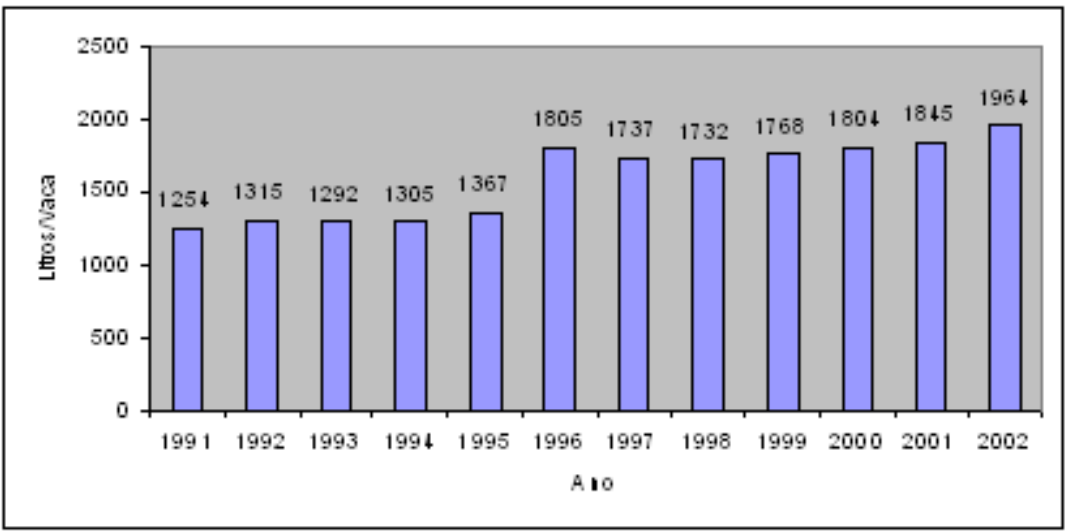

Figura 1 - Produtividade litros/vaca do Rio Grande do Sul. Fonte: IBGE - Pesquisa da Pecuária Municipal.

Já no que se refere ao panorama do setor lácteo estadual (Tabela 3), observam-se níveis de concentração espacial na produção de leite, destacando-se a mesorregião Noroeste do Rio Grande do Sul, por contribuir, no ano de 2002, com 57,19\% (ou 1.332 milhões de litros de leite) da produção estadual, seguida, de longe, pela mesorregião Nordeste, com uma participação de 12,52\% (ou 291 milhões de litros de leite). Note-se também que, entre os anos de 1991 e 2002, a produtividade da mesorregião Nordeste cresceu de 1.394 para 2.205 litros/vaca/ano, ou seja, um incremento de $58,18 \%$ na eficiência da produção, isto é, ganhos de produtividade situados acima das médias estadual e nacional. Finalmente, deve-se destacar que, no período analisado, todas as mesorregiões obtiveram ganhos de produtividade relevantes. 
No entanto, observando a Tabela 4, percebe-se a grande importância que o Noroeste Rio-Grandense apresenta, comparando-se com as principais mesorregiões produtoras de leite do Brasil. Posiciona-se em segundo lugar no ranking nacional em produção e em terceiro lugar em produtividade, perdendo no primeiro caso para a mesorregião do Triângulo Mineiro e, em produtividade, para o Centro Oriental Paranaense e Oeste Catarinense. 
Tabela 4 - Ranking das principais mesorregiões produtoras do País 1991-2002

\begin{tabular}{|c|c|c|c|c|c|c|c|c|}
\hline & \multirow[b]{2}{*}{ UF } & \multirow[b]{2}{*}{ Me sorregião } & \multicolumn{3}{|c|}{$\begin{array}{c}\text { Produção de Leite } \\
\text { (milhões litros) }\end{array}$} & \multicolumn{3}{|c|}{$\begin{array}{c}\text { Produtividade } \\
\text { (litros/vaca/ano) }\end{array}$} \\
\hline & & & 1991 & 2001 & 2002 & 1991 & 2001 & 2002 \\
\hline 1 & $M G$ & Triângulo Mineiroítal to Paranaiba & 953 & 1.366 & 1.461 & 720 & 1.185 & 1.199 \\
\hline 2 & RS & Noroeste Rio-Grandense & 647 & 1.293 & 1.332 & 1.394 & 2.120 & 2.205 \\
\hline 3 & GO & Sul-Goiano & 605 & 1.094 & 1.161 & 504 & 1.218 & 1.264 \\
\hline 4 & $\mathrm{MG}$ & Sul / Sudoeste de Minas & 840 & 1.006 & 1.047 & 1.232 & 1.569 & 1.564 \\
\hline 5 & $\mathrm{SC}$ & Oeste Catarinense & 283 & 666 & 791 & 1.146 & 1.947 & 2.224 \\
\hline 6 & GO & Centro-Goiano & 316 & 711 & 740 & 520 & 1.094 & 1.108 \\
\hline 7 & RO & Les te Rond oniense & 240 & 425 & 584 & 578 & 964 & 987 \\
\hline 8 & $M G$ & Zona da Mata & 532 & 586 & 580 & 1.193 & 1.443 & 1.435 \\
\hline 9 & $M G$ & Oeste de Minas & 293 & 530 & 528 & 1.003 & 1.743 & 1.799 \\
\hline 10 & $M G$ & Central Mineira & 250 & 537 & 521 & 1.001 & 1.689 & 1.822 \\
\hline 11 & $M G$ & Me tropolitana de Belo Horizonte & 299 & 469 & 479 & 1.049 & 1.712 & 1.732 \\
\hline 12 & PA & Sudeste Paraense & 134 & 358 & 467 & 278 & 741 & 593 \\
\hline 13 & PR & Oest & 253 & 3 & 436 & 1.329 & 1 & 2.053 \\
\hline 14 & $M G$ & Vale do Rio Doce & 352 & $57 x$ & 415 & 766 & 1.099 & 1.095 \\
\hline 15 & SP & São José do Rio Preto & 351 & 369 & 382 & 654 & 818 & 830 \\
\hline 16 & $\mathrm{PR}$ & Sud oeste Paranaense & 162 & 318 & 354 & 1.375 & 1.882 & 1.892 \\
\hline 17 & $M G$ & Horoeste de Minas & 159 & 320 & 344 & 611 & 1.509 & 1.482 \\
\hline 18 & $\mathrm{PR}$ & Centro Oriental Paranaense & 148 & 320 & 322 & 2.175 & 2.883 & 2.806 \\
\hline 19 & RS & Nordeste Rio-Grandense & 199 & 233 & 292 & 1.234 & 1.371 & 1.845 \\
\hline 20 & $M G$ & Campos das Vertentes & 238 & 265 & 265 & 1.533 & 1.866 & 1.928 \\
\hline 21 & PR & Norte Central Paranaense & 197 & 245 & 253 & 1.006 & 1.296 & 1.329 \\
\hline 22 & $M G$ & Norte de Minas & 175 & 234 & 235 & 495 & 760 & 800 \\
\hline 23 & $\mathrm{PR}$ & Noroeste Paranaense & 179 & 227 & 231 & 822 & 1.220 & 1.258 \\
\hline 24 & RS & Centro Oriental Rio-Grandense & 164 & 201 & 205 & 1.255 & 1.811 & 1.864 \\
\hline 25 & BA & Centro Sul Baiano & 219 & 215 & 204 & 451 & 452 & 446 \\
\hline 26 & SP & Campinas & 266 & 196 & 201 & 1.457 & 1.782 & 1.870 \\
\hline 27 & SP & Vale do Paraiba Paulis ta & 225 & 194 & 200 & 1.365 & 1.244 & 1.191 \\
\hline 28 & SP & Ribeirão Pre & 261 & 178 & 167 & 1.000 & 1.338 & 1.345 \\
\hline
\end{tabular}


Observando a Tabela 5, verificam-se as principais microrregiões produtoras do Rio Grande do Sul, destacando-se a microrregião de Passo Fundo, com a maior produção de leite do estado, com uma produção de 221 milhões de litros, seguida por Três Passos, em segundo lugar, com 163 milhões, e, em terceiro, pela microrregião de Santa Rosa, com uma produção de 151 milhões. 
Tabela 5 - Principais microrregiões produtoras do Rio Grande do Sul -2002

\begin{tabular}{|c|c|c|c|}
\hline Ronking & Mirrorregiăo Geográfica & Produçăo (mil lintros) & Podutividade (litrosivacas) \\
\hline $1^{*}$ & Passo Fundo & 221651 & 2664 \\
\hline 2 & Três Passos & 163808 & 2.199 \\
\hline 3 & Santa Rosa & 151.198 & 2247 \\
\hline $4^{*}$ & Lajeado-Estrela & 144.150 & 2.415 \\
\hline 5 & Ijuí & 124374 & 2.795 \\
\hline 6 & Guaporé & 119620 & 2676 \\
\hline$\gamma$ & Caxias do Sul & 104815 & 2.100 \\
\hline $8^{\circ}$ & Erechim & 103932 & 1.785 \\
\hline$g$ & Frederico Westphalen & 97.735 & 1596 \\
\hline $10^{\circ}$ & Cnuz Alta & 97.476 & 2.723 \\
\hline $11^{*}$ & Pelotas & 95.488 & 1810 \\
\hline $12^{\circ}$ & Sarto Ângelo & 86.688 & 1.715 \\
\hline $13^{\circ}$ & Ceno Largo & 78.205 & 1881 \\
\hline $14^{\circ}$ & Caraminho & 67.804 & 2.141 \\
\hline $15^{\circ}$ & Vacaria & 67.278 & 1055 \\
\hline $16^{\circ}$ & Hão-Me-Toque & 60.836 & 3.241 \\
\hline $17^{\circ}$ & Samanduva & 51.276 & 2.417 \\
\hline $18^{\circ}$ & Sarta Cruz do Sul & 46.559 & 1283 \\
\hline $19^{\circ}$ & Gramado_Canela & 46.297 & 2200 \\
\hline $20^{\circ}$ & Porto Alege & 45.444 & 2.180 \\
\hline $21^{\circ}$ & Carrpanha Meridional & 41.925 & 2.489 \\
\hline $22^{\circ}$ & Montenegro & 40.188 & 1986 \\
\hline $23^{\circ}$ & Samtiago & 38.266 & 1.444 \\
\hline $24^{\circ}$ & Carmanha Ocidertal & 36.200 & 1241 \\
\hline $25^{\circ}$ & Santa Maria & 36.148 & 1095 \\
\hline $25^{\circ}$ & Soledade & 27.395 & 1.727 \\
\hline $27^{\circ}$ & Seras de Sudeste & 21.831 & 1090 \\
\hline $28^{\circ}$ & Carrqanha Certral & 20.697 & 1235 \\
\hline $2^{*}$ & Restinga Seca & 20.257 & 1.129 \\
\hline $30^{\circ}$ & Litoral Lagunar & 18.044 & 1932 \\
\hline $31^{\circ}$ & Osónio & 17.049 & 1250 \\
\hline $32^{\circ}$ & Cachoeira do Sul & 14.044 & 1011 \\
\hline $33^{\circ}$ & Camaquã & 9.237 & 1.448 \\
\hline $34^{\circ}$ & São Jerôrumo & 6.950 & 1899 \\
\hline $35^{\circ}$ & Jąuaว̃o & 6.733 & 1.032 \\
\hline
\end{tabular}


Merece destaque nesta análise a microrregião de Não-Me-Toque, com uma produtividade de 3.241 litros/vaca, muito maior que a média nacional e também estadual, comparando-se com países extremamente competitivos no setor, como a Argentina, com produtividade média de 3.565 litros/vaca, e Nova Zelândia, com produtividade média de 3.703 litros/vaca.

Em síntese, o conjunto de informações apresentadas mostra que o setor lácteo do Estado do Rio Grande do Sul apresenta uma performance econômica setorial relevante, uma vez que se constitui num grande produtor de leite no âmbito nacional e seu nível de produtividade elevado coloca-o entre os mais eficientes do país.

\section{Dimensão econômica do complexo lácteo}

Tendo em vista o panorama da produção e produtividade do complexo lácteo gaúcho em nível nacional e por regiões, a questão é: qual a dimensão econômica desse complexo? A análise a seguir demonstra as dimensões do complexo lácteo quanto ao PIB, emprego e rendimento salarial, utilizando como benchmark a matriz de insumo-produto estadual de 1998.

\subsection{O Produto Interno Bruto}

O agronegócio gaúcho, medido a preços básicos, chegou a responder por 36,27\%, ou R\$21.884 milhões (Tabela 6), do PIB estadual de 1998. Já o produto do complexo lácteo (Tabela 7), por sua vez, responde por $2,46 \%$ e $6,77 \%$ do PIB estadual e do agronegócio, respectivamente. 
Tabela 6 - O agronegócio na estrutura do PIB do Estado do Rio Grande do Sul em 1998 a preços básicos (em R \$ milhões e percentual)

\begin{tabular}{|c|c|c|c|}
\hline Apregados & $\begin{array}{c}\text { Valores a } \\
\text { preços básicos }\end{array}$ & $\begin{array}{c}\text { Participaçăo } \\
\text { relativa dos } \\
\text { Agregados no PB } \\
\text { estadual } \\
\end{array}$ & $\begin{array}{l}\text { Participaçăo relativa } \\
\text { dos } \\
\text { agregados no HB do } \\
\text { agronegpicio }\end{array}$ \\
\hline I Irsumos Agropedánios & 1.254 & $2,08 \%$ & $5,73 \%$ \\
\hline II Produto Agropeouáno & 5.491 & $9,10 \%$ & $25,09 \%$ \\
\hline III Agrointístria & 6.465 & $10,71 \%$ & $29,54 \%$ \\
\hline TV Agrosserviços & 8.674 & $14,37 \%$ & $39,63 \%$ \\
\hline $\begin{array}{l}\text { PIB do agronegócio (I + II + } \\
\text { III+ IV) }\end{array}$ & 21.884 & $36,27 \%$ & $100,00 \%$ \\
\hline V Indistria & 12.440 & $20,62 \%$ & \\
\hline VI Serviços Industriais & 9.154 & $15,17 \%$ & \\
\hline VII Serviços & 16862 & $27,95 \%$ & \\
\hline $\begin{array}{l}\text { PIB do resto da economia (V + } \\
\text { VI + VII) }\end{array}$ & 38.456 & $63,73 \%$ & \\
\hline $\begin{array}{l}\text { PIB Estadual (I + II + III+ IV } \\
+ \text { V + VI + VII ) }\end{array}$ & 60.340 & $100,00 \%$ & \\
\hline
\end{tabular}

Do valor total do complexo lácteo de $\mathrm{R} \$ 1.481,41$ milhões, $\mathrm{R} \$ 38$ milhões $(2,57 \%)$ correspondiam às compras de insumos ou gastos em custeio e recria feitos pelos produtores de leite (agregado I ou insumos do leite); R \$ 309,28 milhões (ou 20,88\%) correspondiam à agregação do valor por parte dos produtores em atividades puramente de produção do leite (agregado II ou produto do leite); $\mathrm{R} \$ 569,01$ milhões (ou 38,41\%) eram gerados através do processo de industrialização do leite (agregado III ou agroindústria do leite); e R \$565,12 milhões (ou 38,15\%), via serviços de transporte, armazenamento e comercialização final do leite natural e de mercadorias ou produtos agroindustriais derivados do leite (agregado IV ou agrosserviços do leite). 
Tabela 7 - O PIB do complexo lácteo gaúcho a preços básicos (em $\mathrm{R}$ \$ milhões e percentual)

\begin{tabular}{|c|c|c|c|c|}
\hline Agregados & $\begin{array}{l}\text { Valores } \\
\text { apres os } \\
\text { básic os }\end{array}$ & $\begin{array}{l}\text { Partidipação } \\
\text { relativa dos } \\
\text { agregados no } \\
\text { PIB do } \\
\text { complexo } \\
\text { lácteo }\end{array}$ & $\begin{array}{l}\text { Participação } \\
\text { relativa dos } \\
\text { agregados do } \\
\text { complexo lácteo } \\
\text { no PIB do } \\
\text { agronegócio }\end{array}$ & $\begin{array}{l}\text { Participacão } \\
\text { relativa do } \\
\text { PIB do } \\
\text { complexo } \\
\text { lácteo no PIB } \\
\text { etadual }\end{array}$ \\
\hline I Irsumos do Lete & $38 \rho 0$ & $2,57 \%$ & $3,03 \%$ & \\
\hline $\begin{array}{l}\text { II Produto do Le ite } \\
\text { II Agrointistria do }\end{array}$ & 309,28 & $20,88 \%$ & $5,63 \%$ & \\
\hline $\begin{array}{l}\text { Leite } \\
\text { IV Agrosservicos }\end{array}$ & 569,01 & $38,41 \%$ & $8,80 \%$ & \\
\hline $\begin{array}{l}\text { do Leite } \\
\text { PIB do complexo } \\
\text { lícteo ( I + II + III+ }\end{array}$ & 565,12 & $38,15 \%$ & $6,52 \%$ & \\
\hline (V) & 1481,41 & $100,00 \%$ & $6,77 \%$ & $2,46 \%$ \\
\hline
\end{tabular}

As informações de 1998 indicam também que o agregado II, ou produto do leite, está fortemente vinculado ao setor urbano e, portanto, interconectado ao resto da economia, uma vez que, do produto total do complexo lácteo, 20,88\% são gerados no campo e 79,13\% (agregados I, III e IV), na sua maior parte, no setor urbano.

Esse fato, por sua vez, corrobora as afirmações de Montoya e Finamore (2004), de que o complexo lácteo está constituído de setores-chave, com fortes encadeamentos não só para o agronegócio, como também para a economia gaúcha como um todo.

Em síntese, a composição do complexo lácteo confirma que seus agregados adicionam significativo valor às matérias-primas, sendo as atividades de processamento (agregado III) e distribuição final (agregado IV) as que apresentam maior propulsão. 


\subsection{O emprego no complexo lácteo gaúcho}

Considerando que o nível de emprego da mão-de-obra é uma preocupação pública e um tópico de pesquisa permanente, a análise do papel que cumpre ao complexo lácteo gaúcho nessa função econômica e social constitui-se importante na medida em que possibilite identificar elementos fundamentais para a política econômica.

Como mostra a Tabela 8 , do total de trabalhadores no estado (4.907.730 empregados), 47,68\% (ou 2.328.067 pessoas) estão empregados no agronegócio. Nesse contexto, verifica-se que o complexo lácteo (Tabela 9) desempenha um papel importante na economia gaúcha, pois emprega um total de 118.603 pessoas, ou seja, do total de trabalhadores no estado e/ou no agronegócio, 2,42\% e 5,07\% estão empregados no complexo lácteo. Embora essas informações do complexo, quando associadas à sua participação no PIB estadual (2,46\%) e no do agronegócio $(6,77 \%)$, salientem que a importância relativa das atividades do complexo lácteo no emprego é menor que no valor adicionado, também sugerem que o complexo lácteo, em média, detém, em relação ao agronegócio, atividades que utilizam em seus processos produtivos tecnologias mais intensivas no uso de capital que de mão-de-obra. 
Tabela 8 - Pessoal ocupado no agronegócio no estado do Rio Grande do Sul em 1998 (número de empregos e percentual)

\begin{tabular}{|c|c|c|c|}
\hline Agregados & $\begin{array}{l}\text { Número de } \\
\text { enpregados }\end{array}$ & $\begin{array}{l}\text { Participaçăo } \\
\text { relativa dos } \\
\text { agregados no } \\
\text { estado }\end{array}$ & $\begin{array}{l}\text { Participaçăo } \\
\text { relativa dos } \\
\text { agregados no } \\
\text { agronegicio } \\
\end{array}$ \\
\hline I Insumos Agropecuánios & 167.102 & $3,40 \%$ & $7,14 \%$ \\
\hline II Produto Agropecuánio & 1.115 .704 & $22,73 \%$ & $47,67 \%$ \\
\hline III Agroindístria & 434014 & $8,84 \%$ & $18,55 \%$ \\
\hline IV Agors serviços & 623247 & $12,70 \%$ & $26,63 \%$ \\
\hline $\begin{array}{l}\text { Pessoal ocupado no agronegócio (I + II + } \\
\text { III IV) }\end{array}$ & 2.340 .067 & $47,68 \%$ & $100,00 \%$ \\
\hline V Indistria & 698240 & $14,23 \%$ & \\
\hline VIServiģas Industriais & 657.787 & $13,40 \%$ & \\
\hline VII Servigos & 1211.636 & $24,69 \%$ & \\
\hline $\begin{array}{l}\text { Pessoal ocupado no resto da economia (V } \\
\text { + VI + VII) }\end{array}$ & 2567.663 & $\$ 2,32 \%$ & \\
\hline $\begin{array}{l}\text { Pessoal ocupado no estado (I + II + III+ } \\
\underline{\text { V + V + VI + VII) }}\end{array}$ & 4907.730 & $100,00 \%$ & \\
\hline
\end{tabular}

Fonte: Finamore e Montoya (2003).

Por sua vez, na análise da distribuição do total de trabalhadores empregados no complexo lácteo (Tabela 9), observa-se o destaque do agregado II ou produto do leite $(45,97 \%)$ sobre os demais agregados, indicando, com isso, que as atividades rurais propriamente ditas são as que empregam maior mão-de-obra, se comparadas com o agrosserviço $(34,24 \%)$, a agroindústria $(16,61 \%)$ e os insumos do leite $(3,18 \%)$. 
Tabela 9 - Pessoal ocupado no complexo lácteo gaúcho (número de empregos e percentual)

\begin{tabular}{|c|c|c|c|c|}
\hline Agregados & $\begin{array}{l}\text { Número de } \\
\text { empreges }\end{array}$ & $\begin{array}{l}\text { Partioipasão } \\
\text { relativa dos } \\
\text { agregados no } \\
\text { complexo lácteo }\end{array}$ & $\begin{array}{l}\text { Participasão } \\
\text { relativa dos } \\
\text { agregados do } \\
\text { complexo } \\
\text { lácteo no } \\
\text { agronegócio }\end{array}$ & $\begin{array}{c}\text { Participafão } \\
\text { relativa do } \\
\text { complexo } \\
\text { lácteo no } \\
\text { etado }\end{array}$ \\
\hline I Insumos do Le ite & 3774 & $3,18 \%$ & $2 \not 26 \%$ & \\
\hline II Produto do Leite & 54524 & $4597 \%$ & $489 \%$ & \\
\hline III Agroindústria do Le ite & 19699 & $16 f 1 \%$ & $4,54 \%$ & \\
\hline $\begin{array}{l}\text { IV Agrosserviços do Leite } \\
\text { Pessoal ocupado no } \\
\text { complexo ( I + II + III + IV) }\end{array}$ & $\begin{array}{r}40605 \\
118603\end{array}$ & $34,24 \%$ & $6,52 \%$ & $2,42 \%$ \\
\hline
\end{tabular}

Em síntese, embora as informações indiquem que o complexo lácteo como um todo gere 5,07\% do emprego no agronegócio, elas também indicam que políticas de investimento diferenciadas por agregados que objetivem o aumento do emprego encontrarão seus alicerces nos agregados II e IV, uma vez que, em conjunto, detêm $80,21 \%$ e $4,07 \%$ dos empregados do complexo lácteo e do agronegócio gaúcho, respectivamente.

\subsection{A renda do trabalhador no agronegócio gaúcho}

Em geral, verifica-se a partir das Tabelas 10 e 11 que o complexo lácteo contribui com $1,82 \%$ e $5,29 \%$ do rendimento salarial no estado e no agronegócio, respectivamente. As informações do pessoal ocupado e dos rendimentos salariais assinalam que a remuneração média da mãode-obra no complexo lácteo, por um lado, é menor que a média do estado e, por outro, maior que a do agronegócio. Enquanto o rendimento salarial anual médio por trabalhador no complexo lácteo é de $\mathrm{R} \$ 4.123$ ou 31,72 SM, no agronegócio, no estado e no resto da economia é de $\mathrm{R} \$ 3.953,16$ ou 30,40 SM, de R $\$ 5.469,31$ ou 42,07 SM e de R $\$ 6.851,08$ ou 52,70 SM, respectivamente. 
A análise mais particularizada dos rendimentos salariais por agregados mostra que esses diferenciais salariais podem estar associados ao maior ou menor grau de qualificação da mão-de-obra, uma vez que tanto no agronegócio como no complexo lácteo as menores remunerações encontram-se nos trabalhadores rurais ( $\mathrm{R} \$ 1.832,65$ ou $14,10 \mathrm{SM})$ e as maiores, nos trabalhadores dos serviços e da indústria.

Embora na literatura sobre diferenciais salariais se considere como fato que a mão-de-obra no setor rural é menos qualificada que no setor urbano e, portanto, menos remunerada, não existe consenso sobre esse tipo de relação entre a mão-de-obra empregada na indústria e aquela usada nos serviços.

Entretanto, se for aceita a hipótese de quanto mais qualificada a mãode-obra, maior o nível de remuneração, pode-se inferir — pelo diferencial de salários entre os agregados serviços (serviços industriais, serviços, agrosserviços e agrosserviços do leite) e agregados industriais (indústria, agroindústria e agroindústria do leite) — que, tanto na economia gaúcha como um todo como no agronegócio e no complexo lácteo, os agregados serviços empregam uma mão-de-obra mais qualificada e, portanto, mais bem remunerada. 
Tabela 10 - Rendimentos salariais do agronegócio no Estado do Rio Grande do Sul em 1998 (em R\$ milhões e percentual)

\begin{tabular}{|c|c|c|c|c|c|c|}
\hline \multirow[t]{2}{*}{ Agregados } & \multirow[t]{2}{*}{ Valores } & \multirow[t]{2}{*}{$\begin{array}{l}\text { Participacão } \\
\text { relativa dos } \\
\text { agregados no } \\
\text { etado }\end{array}$} & \multirow[t]{2}{*}{$\begin{array}{l}\text { Participação } \\
\text { relativa dos } \\
\text { Agregados no } \\
\text { agronegócio }\end{array}$} & \multicolumn{2}{|c|}{$\begin{array}{l}\text { Rendimento } \\
\text { salarial anual } \\
\text { médio por } \\
\text { trabalhador }\end{array}$} & \multirow{2}{*}{$\begin{array}{l}\text { Participasano } \\
\text { relativa dos } \\
\text { rendimentos } \\
\text { salariais no } \\
\text { PIB dos } \\
\text { agregados }\end{array}$} \\
\hline & & & & $\mathrm{RS}$ & $\mathrm{SM}^{*}$ & \\
\hline $\begin{array}{c}\text { I Insmmos } \\
\text { Agyopecuários }\end{array}$ & 489 & $1,82 \%$ & $5,28 \%$ & 2924,50 & 22,49 & $3897 \%$ \\
\hline $\begin{array}{r}\text { II Prodito } \\
\text { Agropecuário }\end{array}$ & 2045 & $7,62 \%$ & $22,10 \%$ & 1832,65 & 14,09 & $3723 \%$ \\
\hline III Agrointústria & 2209 & $8,23 \%$ & $23,88 \%$ & 5090,63 & 39,15 & $34,18 \%$ \\
\hline W Agrosserwiços & 4508 & $16,79 \%$ & $4873 \%$ & 7232,87 & 55,63 & $5197 \%$ \\
\hline $\begin{array}{l}\text { do agronegó dio } \\
(\mathrm{I}+\mathrm{II}+\mathrm{II}+\mathrm{IV})\end{array}$ & 9251 & $34,46 \%$ & $100,00 \%$ & 3953,16 & 30,40 & $42,27 \%$ \\
\hline V Indústria & 4070 & $15,16 \%$ & & 5828,90 & 44,83 & $3272 \%$ \\
\hline $\begin{array}{l}\text { VI Serviços } \\
\text { Industriais }\end{array}$ & 4.758 & $17,72 \%$ & & 7232,87 & 55,63 & $5197 \%$ \\
\hline $\begin{array}{l}\text { VII Serviços } \\
\text { Renimento sabrial }\end{array}$ & 8.764 & $32,65 \%$ & & 7232,87 & 55,63 & $5197 \%$ \\
\hline $\begin{array}{l}\text { do resto da } \\
\text { exonomia }(\mathrm{V}+\mathrm{VI}+ \\
\text { VII) }\end{array}$ & 17.591 & $65,54 \%$ & & 6851,08 & 52,70 & $4574 \%$ \\
\hline $\begin{array}{l}\text { Rentimento sabrial } \\
\text { do estado } \\
(\mathbf{I}+\mathrm{II}+\mathrm{III}+\mathrm{IV}+\mathrm{V} \\
+\mathrm{VI}+\mathrm{VII}) \\
\end{array}$ & 26.842 & $100,00 \%$ & & $5,469,31$ & 42,07 & $44,48 \%$ \\
\hline
\end{tabular}

* SM: salário mínimo de 1998 ( R \$ 130,00).

Fonte: Finamore e Montoya (2003).

Uma outra forma de visualizar o rendimento salarial é através da parcela da renda ou do valor adicionado apropriada pelos trabalhadores. Essa análise revela a relação entre trabalhadores e capitalistas nos diferentes setores da economia, ou seja, a participação relativa dos rendimentos salariais no PIB dos agregados, tanto da economia gaúcha como do seu agronegócio e complexo lácteo.

Vale salientar que nas Tabelas 10 e 11 não são apresentadas as parcelas apropriadas pelos empresários e pelo governo, em virtude da não- 
desagregação desses dados pela FEE no momento em que foi construída a matriz insumo-produto do Rio Grande do Sul.

Tabela 11 - Rendimento salarial no complexo lácteo gaúcho (em R\$ milhões e percentual)

\begin{tabular}{|c|c|c|c|c|c|c|c|}
\hline \multirow[t]{2}{*}{ Agegados } & \multirow[t]{2}{*}{ vilares } & \multirow[t]{2}{*}{$\begin{array}{l}\text { Participacão } \\
\text { relativa dos } \\
\text { apregadosno } \\
\text { complexo } \\
\text { kicteo }\end{array}$} & \multicolumn{2}{|c|}{$\begin{array}{c}\text { Rendimento } \\
\text { salarial mual } \\
\text { mótio pa } \\
\text { trabahada }\end{array}$} & \multirow{2}{*}{ 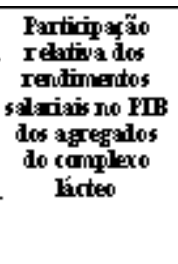 } & \multirow{2}{*}{$\begin{array}{l}\text { Paticiparão } \\
\text { reling dos } \\
\text { agregaios do } \\
\text { complexo hicteo } \\
\text { no agronegócio }\end{array}$} & \multirow[t]{2}{*}{$\begin{array}{l}\text { Partiqipanaso } \\
\text { relativa do } \\
\text { complexo } \\
\text { kiteo no } \\
\text { etado }\end{array}$} \\
\hline & & & $\mathrm{R} \&$ & $\mathrm{SM}^{*}$ & & & \\
\hline I husmos do Leite & 15 & $3,08 \%$ & 3.989 & 30,68 & $39,62 \%$ & $3,08 \%$ & \\
\hline $\begin{array}{l}\text { II Protuto do Leite } \\
\text { III Agrovintistrin }\end{array}$ & 100 & $20,43 \%$ & 1.833 & 14,10 & $3231 \%$ & $4, \infty 9 \%$ & \\
\hline $\begin{array}{l}\text { do Leite } \\
\text { TV Agroservicos }\end{array}$ & 80 & $16,43 \%$ & 4.078 & 3137 & $14,12 \%$ & $3,64 \%$ & \\
\hline $\begin{array}{l}\text { do Leite } \\
\text { Renulimato solyisl } \\
\text { no camplexo (I + II }\end{array}$ & 294 & $60,06 \%$ & 7.233 & 55,64 & $5197 \%$ & $6,20 \%$ & \\
\hline+ III + IV) & 480 & 100,000 & 4.123 & 31,72 & 33,000 & $5,200 \%$ & $1,82 \%$ \\
\hline
\end{tabular}

* SM: salário mínimo de 1998 (R \$ 130,00).

Fonte: Dados da pesquisa.

Dentre os agregados do estado, do agronegócio e do complexo lácteo, os trabalhadores que têm maior participação são aqueles que estão ligados às atividades de serviços (agregado IV), com aproximadamente 52\%. Os trabalhadores das atividades de insumos do leite (agregado I) apropriam-se de $39,62 \%$, seguidos pelos trabalhadores da produção de leite $(32,31 \%)$ e da agroindústria do leite $(14,12 \%)$, com este último destacando-se, dentre os agregados do complexo lácteo, como aquele em que menos os trabalhadores se apropriam da renda.

Cabe salientar, nesse contexto, que a parcela do valor adicionado apropriada pelos trabalhadores do complexo lácteo por agregados mostra, na agroindústria do leite (agregado III), processos produtivos modernos com tecnologias mais intensivas no uso de capital que de mão-de-obra. Isso porque, dos agregados do complexo lácteo e da economia gaúcha como um todo, a agroindústria do leite apresenta-se com a menor participação relativa na apropriação da renda $(14,12 \%)$. 


\section{Conclusões}

O artigo teve como objetivo analisar alguns aspectos do desempenho do complexo lácteo nos contextos regional e nacional, bem como, para o ano de 1998, mensurar o PIB, o número de empregos e a renda salarial do complexo lácteo gaúcho.

Verificou-se que o complexo lácteo gaúcho é um grande produtor de leite nacional e que seu nível de competitividade o situa entre os mais eficientes produtores do país. Isso porque, em termos de produtividade, no ranking nacional, o estado situa-se no primeiro lugar e, em termos de produção, no terceiro lugar. Cabe salientar também que a mesorregião Noroeste Rio-Grandense é a segunda maior bacia leiteira do país e seus níveis de produtividade estão em constante crescimento.

Constatou-se também que o complexo lácteo gaúcho responde por 6,77\% do PIB do agronegócio a preços básicos, indicando, com isso, que parte importante do perfil do agronegócio está determinada pelas atividades do complexo lácteo.

A análise dos agregados do complexo lácteo, por outro lado, indica que a produção de leite está fortemente integrada com o setor urbano e emprega 118.603 trabalhadores, o que perfaz $5,07 \%$ e $2,42 \%$ do total de trabalhadores do agronegócio e do estado, respectivamente.

O conjunto das informações de pessoal ocupado com os respectivos rendimentos salariais permitiu observar diferenciais salariais: o rendimento salarial médio do complexo lácteo é menor que o do estado e maior que o do agronegócio.

A partir da parcela do valor adicionado apropriada pelos trabalhadores, identificou-se que a agroindústria do leite detém processos produtivos modernos, com tecnologias mais intensivas no uso de capital que de mãode-obra. Isso porque, dos agregados do complexo lácteo e da economia 
gaúcha como um todo, a agroindústria do leite apresenta-se com a menor participação relativa na apropriação da renda $(14,12 \%)$.

Portanto, conclui-se que o complexo lácteo constitui-se num importante componente do complexo lácteo nacional e do agronegócio gaúcho, sendo seu desempenho, dados os fortes encadeamentos que apresenta com o setor urbano, fundamental para o desenvolvimento econômico do Estado do Rio Grande do Sul.

\section{Referências}

DAVIS, J. \& GOLDBERG, R. A concept of agribusiness. Boston: Harvard University, 1957.

EMBRAPA GADO DE LEITE . www.cnpgl.embrapa.br.

FEE. Matriz de insumo-produto do Rio Grande do Sul. CD-Rom. 1998.

FINAMORE, E. B. \& MONTOYA, M. A. Pib, tributos, emprego, salários e saldo comercial no agronegócio gaúcho. Revista Ensaios Econômicos da FEE. Porto Alegre - RS: FEE editora, v 24 , n. 1, p. 93-126, abril de 2003.

FINAMORE, E. B. O crescimento setorial da economia brasileira no período 1985/96: uma análise de insumo-produto. Tese (doutorado). Universidade Federal de Viçosa. Viçosa - MG. 2001. 166 p.

FURTUOSO, M. O produto interno bruto do complexo agroindustrial brasileiro. Tese (Doutorado) - Esalq/USP, 1998.

IBGE - Instituto Brasileiro de Geografia e Estatística. www.ibge.gov.br. 
JANK, Marcos Sawaya. Competitividade do Sistema Agroindustrial do Leite. 2000. 271p.

LAUSCHNER, R. Agribusiness, cooperativa e produtor rural. São Leopoldo: Unisinos, 1993.296 p.

MALASSIS, L. Analyse du complexe agro-analimentaire d'apres la comptabilité nacionale française. Économies et societés. Paris, v. 3, n. 9, p. 1667-1687, set. 1969 (Cahiers de L’I.S.E.A, Série “ Developpement économique et agriculture”, dirigida por Michel Cépéde, Luois Malassis e Joseph Klatzmann).

MONTOYA, M. A. \& FINAMORE, E. B. Delimitação e encadeamentos de sistemas agroindustriais: o caso do complexo lácteo gaúcho. Texto para discussão (UPF). Passo Fundo - RS: UPF editora, n. 03, p. 17, 2004.

MONTOYA , M. A. \& FINAMORE, E. B. Evolução do PIB do agronegócio brasileiro de 1959 a 1995: uma estimativa na ótica do valor adicionado. Revista Teoria e Evidencia Econômica (UPF). Passo Fundo - RS: UPF editora, v 9 , n. 16, p. 9-24, maio de 1991.

MONTOYA, M. A. \& GUILHOTO, J. J. M. O agronegócio brasileiro entre 1959 e 1995: dimensão econômica, mudança estrutural e tendências. In: Montoya, M. A., Parré, J. L. (Eds.) O agronegócio brasileiro no final do século XX. Passo Fundo - RS: Ediupf, p. 3 - 32, 2000.

MONTOYA, M. A. et. Al (Org.) O agronegócio brasileiro e dos Estados da Região SUL: dimensão econômica e tendências estruturais. Passo Fundo - RS: UPF editora, 2002, p.95.

MONTOYA, M. A. et. al., O agronegócio nos estados da região sul no período de 1985 a 1995. Revista Economia Aplicada (USP), v. 5, n. 1, p.99-127, jan./mar. 2001. 


\begin{abstract}
This article looks for measuring and characterizing the milk's agribusiness of Rio Grande do Sul economy. The methodology used indicators of sectorial performance and indexes of autonomy of purchases and sales to define the measure of the milk's agribusiness. The data were extracted of the matrix input-output available by the Economy and Statistics Foundation (FEE) of the Rio Grande do Sul for the year 1998. It was verified that the state milk's agribusiness answers, to basic price, for $6,77 \%$ of state's agribusiness; it is strongly linked to the urban section in a direct way and it uses 118.603 workers, which employees $5,07 \%$ and $2,42 \%$ of the workers of the state's agribusiness and state's economy, respectively. Thus, it was concluded that the state milk's agribusiness is constituted in an important component of the state's agribusiness and the strong linkages that it presents are fundamental for the economic development of the state.
\end{abstract}

Keywords: milk's agribusiness, input-output, GDP, employee, wage. 


\section{Anexo 1 - Descrição setorial da matriz de insumo-produto do Rio Grande do Sul}

\begin{tabular}{cl}
\hline Setores & Descrição \\
\hline 1 & Arroz em casca \\
2 & Soja em grão \\
3 & Milho em grão \\
4 & Bovinos e suínos \\
5 & Leite natural \\
6 & Aves vivas e ovos \\
7 & Demais produtos agropecuários \\
8 & Produtos metalúrgicos \\
9 & Fabricação e manutenção de tratores, máqui \\
10 & Material elétrico e eletrônico \\
11 & Autoveículos e peças \\
12 & Madeira e mobiliário \\
13 & Papel, celulose, papelão e artefatos \\
14 & Adubos e fertilizantes \\
15 & Demais produtos químicos \\
16 & Produtos petroquímicos \\
17 & Combustíveis e demais produtos do refino \\
18 & Produtos de couro e calçados \\
19 & Arroz beneficiado \\
20 & Demais produtos vegetais beneficiados, exc \\
21 & Fabricação de produtos do fumo \\
22 & Carne bovina e suína \\
23 & Carne de aves abatidas \\
24 & Leite beneficiado e outros laticínios \\
25 & Óleos vegetais em bruto e refinados \\
26 & Demais produtos alimentares \\
27 & Demais nrodutos da indústria \\
& \\
\hline 1 &
\end{tabular}


Eduardo Belisário Finamore \& Marco Antonio Montoya

Fonte: FEE. Matriz de insumo-produto do Rio Grande do Sul. CD-Rom. 1998.

36 Saúde e educação mercantis

37 Serviços prestados às empresas

38 Aluguel de imóveis

$39 \quad$ Aluguel imputado

$40 \quad$ Administração pública

41 Saúde pública

$42 \quad$ Educação pública

43 Serviços privados não-mercantis 
REVISTA DE ECONOMIA E AGRONEGÓCIO, VOL.3, $N^{\circ} 2$ 